\title{
BMJ Open Cognitive development of children with Kawasaki disease and the parenting stress of their caregivers in Taiwan: a case-control study
}

\author{
Liang-Jen Wang (D , , ${ }^{1}$ Zi-Yu Tsai, ${ }^{2}$ Ling-Sai Chang, ${ }^{2}$ Ho-Chang Kuo ${ }^{2,3,4}$
}

To cite: Wang L-J, Tsai Z-Y, Chang L-S, et al. Cognitive development of children with Kawasaki disease and the parenting stress of their caregivers in Taiwan: a case-control study. BMJ Open 2021;11:e042996. doi:10.1136/ bmjopen-2020-042996

- Prepublication history for this paper is available online. To view these files, please visit the journal online (http://dx.doi. org/10.1136/bmjopen-2020042996).

Received 22 July 2020 Accepted 18 May 2021

Check for updates

(c) Author(s) (or their employer(s)) 2021. Re-use permitted under CC BY-NC. No commercial re-use. See rights and permissions. Published by BMJ.

${ }^{1}$ Department of Child and Adolescent Psychiatry,

Kaohsiung Chang Gung

Memorial Hospital and Chang

Gung University College of

Medicine, Kaohsiung, Taiwan,

Kaohsiung, Taiwan

${ }^{2}$ Department of Pediatrics and

Kawasaki Disease Center,

Kaohsiung Chang Gung

Memorial Hospital and Chang

Gung University College of

Medicine, Kaohsiung, Taiwan

${ }^{3}$ Department of Respiratory

Therapy, Kaohsiung Chang Gung

Memorial Hospital and Chang

Gung University College of

Medicine, Kaohsiung, Taiwan

${ }^{4}$ Chang Gung University College

of Medicine, Kaohsiung, Taiwan

Correspondence to

Dr Ho-Chang Kuo;

ericku048@yahoo.com.tw

\section{ABSTRACT}

Objective Kawasaki disease (KD) is an acute form of febrile vasculitis that occurs in early childhood. The multisystemic vasculitis common in patients with $\mathrm{KD}$ may influence blood perfusion in the brain, and thus caregivers of children with KD may feel stress with regard to caring for them. Intravenous immunoglobulin (IVIG) infusion is the standard treatment for acute $\mathrm{KD}$, and the most serious complication of $\mathrm{KD}$ is coronary artery aneurysms (coronary artery lesion (CAL)). This study aimed to investigate the relationships between $\mathrm{KD}$ heterogeneity and the risk of patients' cognitive impairment or caregivers' parenting stress.

Design A case-control study with consecutive sampling. Setting A medical centre (Kaohsiung Chang Gung Memorial Hospital, Taiwan).

Participants This study consisted of 176 patients with KD (mean age: 5.5 years, $60.8 \%$ boys) and 85 healthy children (mean age: 6.4 years, $54.1 \%$ boys).

Primary and secondary outcome measures Based on the children's age, each patient with KD and control subject was administered an assessment using the Mullen Scales of Early Learning or the Wechsler Intelligence Scale, and parenting function of their caregivers was assessed using the Parenting Stress Index (PSI)-Short Form. Results We observed no significant differences in any developmental index, cognitive function or parenting stress between patients with KD and controls. Among the children with KD, IVIG administration nor CAL was associated with children's cognitive scores. However, the caregivers of patients who had CAL suffered from greater PSI total scores than those of patients without CAL. Furthermore, the caregivers who had education levels of a master's degree or above showed less parenting stress than those who had an education level of college or lower. Conclusion Caregivers' education is associated to parenting stress, and caregivers of patients with KD who developed CAL may feel stress about the unpredictable sequela caused by CAL for their children. Such caregivers may require support to fulfil their parenting roles.

\section{INTRODUCTION}

Kawasaki disease (KD) manifests with acute fever, mainly affects children aged $<5$ years, and involves multisystemic vasculitis of unknown aetiology. ${ }^{2}$ Although it occurs
Strengths and limitations of this study

- We carried out a comprehensive study about cognitive impairment of patients with Kawasaki disease (KD) or parenting stress of caregivers.

- This is the first study indicating that caregivers of patients with KD who developed coronary artery aneurysms may feel stress about the unpredictable sequela.

- Owing to small case numbers, it is difficult to make a strong conclusion about cognitive impairment.

- We used a case-control design; therefore, no causal relationships could be identified.

around the world, $\mathrm{KD}$ incidence rates are especially high in East Asia, particularly Japan, Korea and Taiwan. ${ }^{3}$ The primary clinical characteristics of $\mathrm{KD}$ consist of prolonged fever, diffuse mucosal inflammation, bilateral non-purulent conjunctivitis, non-suppurative cervical lymphadenopathy, indurative angioedema of the hands and feet and polymorphous skin rashes. ${ }^{5-7}$ Intravenous immunoglobulin (IVIG) infusion has been established as the standard treatment for acute $\mathrm{KD}^{8}{ }^{8}$ but $10 \%-20 \%$ of patients still show resistance to IVIG therapy and are at high risk for coronary artery complications, ${ }^{9}$ of which, the formation of coronary artery lesions (CALs) is the most serious. ${ }^{10}$ These studies suggest that $20 \%-24 \%$ of children with $\mathrm{KD}$, even when treated with IVIG, still suffer from CAL and $4 \%$ with coronary artery aneurysm formation. ${ }^{11} 12$

In addition to the harm caused to the coronary arteries, KD is also characterised by multisystemic vasculitis and may thus affect blood perfusion and cause inflammatory changes in the brain. ${ }^{13}{ }^{14}$ Central nervous system symptoms, such as lethargy, cranial nerve palsy and prolonged partial seizures, occur in 1\%-30\% of patients with $\mathrm{KD}^{15-18}$ Fortunately, these studies have consistently demonstrated that 
patients with $\mathrm{KD}$ are not associated with cognitive impairment sequelae. ${ }^{19-21}$ However, different responses to IVIG treatment and the development of coronary aneurysms may be related to a discrepancy in patients' immunological profiles or genetic background. ${ }^{22}$ Therefore, the relationships between heterogeneity of $\mathrm{KD}$ and the risk of cognitive impairments warrant further investigation.

Our study revealed that children with $\mathrm{KD}$ suffered acute and prominent impairment in health-related quality of life, and the impairments even exceeded that of children newly diagnosed with cancer. ${ }^{23}$ Furthermore, patients with $\mathrm{KD}$, as well as their caregivers, may consistently worry about patients' potential risk of cardiac event-related death. ${ }^{24}$ With a lack of support and adequate knowledge available at the societal level, patients' caregivers may experience stress from coping with their children's needs and fulfilling their parenting roles. Owing to the uncertainty of the long-term KD prognosis, the parents of children with coronary artery complications suffered from persistent anxiety even years after the acute phase of the illness. ${ }^{25}$ The psychosocial burden of parents is associated with intensity of medical experience and family's psychosocial limitations. ${ }^{26}$ However, the evidence with regarding to parenting stress among caregivers of children with $\mathrm{KD}$ is still scarce. Therefore, recruiting a control group is helpful to compare the cognitive profiles and parenting stress between children with KD and those without KD. ${ }^{27}$

To fill this research gap, we performed a clinical survey to explore the potential factors (eg, responses to IVIG treatment or comorbid CAL) associated with cognitive profiles in patients with KD. In addition, we investigated whether the caregivers of children with $\mathrm{KD}$ and healthy controls exhibited different parenting stress, and to examine the factors correlated to caregivers' parenting stress among children with KD.

\section{METHODS}

\section{Participants}

We recruited a total of 176 patients with KD from the Department of Pediatrics from June 2016 to July 2018, Kaohsiung Chang Gung Memorial Hospital, Taiwan or communities near the hospital. A senior clinician diagnosed patients with $\mathrm{KD}$ in accordance with the recommended universal KD criteria published by the American Heart Association. ${ }^{28}$ The diagnostic criteria of $\mathrm{KD}$ includes fever that lasts longer than 5 days, as well as four of the following five symptoms: diffuse mucosal inflammation with strawberry tongue and fissure lips, bilateral non-purulent conjunctivitis, indurative angioedema of the hands and feet, dysmorphic skin rashes and unilateral cervical lymphadenopathy, as stated in our previous reports. ${ }^{29}$ Once their symptoms were remitted, patients with $\mathrm{KD}$ were administered a developmental or cognitive assessment in either outpatient department or in the ward.

Because most of our patients with $\mathrm{KD}$ were recruited from the outpatient department, we recruited 85 healthy children from communities around Kaohsiung Chang Gung Memorial Hospital or children suffering from upper respiratory tract infection whose symptoms were currently in remission as a control group. We excluded any patients with other immunological diseases (asthma, allergic rhinitis, atopic dermatitis or allergic conjunctivitis) or major physical illnesses (such as genetic, metabolic or infectious conditions).

\section{CAL assessment}

All participants were provided with a structured questionnaire to collect demographic data, such as age, gender and age of onset. We recorded body temperature every 6 hours during the febrile stage. The CAL was defined as a luminal diameter of $>3 \mathrm{~mm}$ in a child aged $<5$ years or $>4 \mathrm{~mm}$ in those aged $\geq 5$ years, when the internal diameter of a segment is 1.5 times or greater than that of an adjacent segment, or when the luminal contour is clearly irregular or has a Z score $>2.5 \mathrm{SD} .{ }^{30}{ }^{31}$ We estimated the Z score of the proximal right coronary artery, left main coronary artery and proximal left anterior descending artery, as well as the maximum $\mathrm{Z}$ score of coronary arteries both at baseline and 6-8 weeks with 2D echocardiography. The body weight and height used to calculate $\mathrm{Z}$ scores were obtained from the Taiwan Society of Pediatric Cardiology website (http://www.tspc.org.tw/service/z_score.asp). The IVIG resistance was defined as persistent or recrudescent fever for at least 36 hours after the end of their IVIG infusion but not $>7$ days. $^{32}$

\section{Neurocognitive assessments}

Each patient with $\mathrm{KD}$ and control subject were administered a developmental or cognitive assessment performed by an experienced child psychologist in a room designed to reduce testing condition variables. Patients aged $<4$ years were assessed using the Mullen Scales of Early Learning (MSEL); patients between the ages of 4 and 7 years were examined using the Wechsler Preschool and Primary Scale of Intelligence-Fourth Edition (WPPSI-IV) and patients aged $>7$ years were tested using the Wechsler Intelligence Scale for Children-Fourth Edition (WISC-IV).

The MSEL, a standardised developmental assessment for newborns through children of age 68 months, offers an overall index of cognitive ability and developmental delay. ${ }^{33}$ It consists of five subscales: Gross Motor (only for children aged $<33$ months), Visual Reception, Fine Motor, Expressive Language and Receptive Language. After scoring each item, the crude scores of each of the five scales are transformed into normalised age-specific scores, referred to as $\mathrm{T}$ scores. The $\mathrm{T}$ scores of all except the Gross Motor Scale are added together and converted into the Early Learning Composite (ELC) score. The MSEL has been applied in Taiwan's toddler samples. ${ }^{21} 34$

The WPPSI-IV is an individually administered, standardised tool for evaluating intelligence in children between the ages of 2 years 6 months and 7 years 7 months. ${ }^{35}$ The test takes about $30-45 \mathrm{~min}$ for children between the ages of 2 years 6 months and 3 years 11 
months and provides a Full-Scale Intelligence Quotient (FSIQ), Verbal Comprehension Index (VCI), Visual Spatial Index (VSI) and Working Memory Index (WMI). For children between the ages of 4 years and 7 years 7 months, it takes about $45-60 \mathrm{~min}$ and provides a FSIQ, VCI, VSI, Fluid Reasoning Index, WMI and Processing Speed Index (PSI).$^{36}$ The WPPSI-IV has been used in clinical study in Taiwan. ${ }^{21} 37$

The WISC-IV is an individually administered and normreferenced tool developed to measure the intelligence of children aged from 6 to 16 years. ${ }^{38}$ The WISC-IV includes 10 core and 5 supplemental subtests. The core subtests create four factor indexes, including the VCI, the Perceptual Reasoning Index, the WMI and the PSI. Meanwhile, the 10 core subtests form the FSIQ. Each factor index, as well as the FSIQ, has a population mean of 100 and an SD of 15. The WISC-IV has been applied for Taiwanese school-aged children in several clinical studies. ${ }^{39} 40$

\section{Parenting stress}

Caregivers' characteristics, including age, gender and education levels, were recorded, and their parenting function was assessed using the Parenting Stress IndexShort Form (PSI-SF). The PSI-SF, a widely adopted selfadministered questionnaire for evaluating parenting stress, includes 36 items (rated on a 5-point Likert scale) and stems directly from the full-length 120-item Parenting Stress Index test. ${ }^{41}$ The PSI-SF provides scores in the following subscales: (a) Parental Distress, (b) ParentChild Dysfunctional Interaction and (c) Difficult Child. The three subscores are added together to yield a total parenting stress score. ${ }^{42}$ Studies have reported that the Chinese version of the PSI-SF is a reliable assessment tool for identifying parenting stress with a need for intervention in clinical practices. ${ }^{43-45}$

\section{Statistical analysis}

All data processing and statistical analyses were performed using the SPSS software, V.14.0. Two-tailed $p$ values $<0.05$ were considered statistically significant.

The sample size calculation was estimated using the $G^{*}$ Power software. Based on the settings of $80 \%$ power, $\mathrm{p}=0.05$, effect size $=0.4$ and allocation ratio $\mathrm{N} 1 / \mathrm{N} 2=2$, the sample size should be 149 in group 1 and 75 in group 2. The common assumptions made when performing a $t$ test include those regarding the scale of measurement, random sampling, normality of data distribution, adequacy of sample size and equality of variance in SD. The assumptions of the $\chi^{2}$ include the data in the cells should be frequencies or counts of cases rather than percentages or some other transformation of the data. The levels (or categories) of the variables are mutually exclusive. Multiple linear regression analysis makes several key assumptions as following: linear relationship, multivariate normality, no or little multicollinearity, no auto-correlation and homoscedasticity. ${ }^{46}$ The literature with regarding to cognitive function and parenting stress among children with KD is still scarce; therefore, the covariates selected for the multiple linear regression model were based on the variables collected in clinical settings.

We used the $\chi^{2}$ test to compare differences in categorical variables between patients with $\mathrm{KD}$ and those without $\mathrm{KD}$. An independent t-test was adopted to compare continuous variables between the two groups. We performed a general linear model to observe the difference in children's cognition and caregivers' stress between patients with KD and controls, controlled for children's age and caregivers' education levels. The cognitive scores of patients who were assessed using the MSEL were set as the ELC scores, and the cognitive scores of those assessed with the WPPSI or WISC-IV were set as the FSIQ. The independent variables were the characteristics of the children and caregivers. Furthermore, multiple linear regression was adopted to determine the factors associated with parental stress among the patients with KD. The dependent variable was set as the total PSI score, and the independent variables were the characteristics of the children and caregivers.

\section{RESULTS}

The study participants consisted of 176 patients with KD (mean age: 5.5 years, $60.8 \%$ boys) and 85 healthy children (mean age: 6.4 years, $54.1 \%$ boys; table 1 ). The healthy children were older than patients with $\mathrm{KD}(\mathrm{p}=0.035)$, and the caregivers in the control group had higher education levels than those in the $\mathrm{KD}$ group $(\mathrm{p}=0.018)$. Apart from this, no significant differences in gender or caregivers' characteristics between children with KD and controls. No significant differences in development scores measured using the MSEL or cognitive scores measured using the WPPSI or WISC-IV were observed between the children with $\mathrm{KD}$ and the healthy controls. When comparing the caregivers of patients with $\mathrm{KD}$ to those of the controls, none of the PSI subscales showed a significant difference.

Of the children with $\mathrm{KD}$, the mean age of $\mathrm{KD}$ onset was 21.6 months; $4 \%$ of them never received IVIG treatment, and $88.6 \%$ and $7.4 \%$ received IVIG treatment once and twice, respectively; $58 \%$ of them had no CAL and $42 \%$ of them had CAL. Table 2 shows the relationship between children's and caregivers' characteristics and the cognitive score among children with $\mathrm{KD}$. We found that neither IVIG administration nor CAL was associated with the cognitive score of children with $\mathrm{KD}$. The characteristics of children and caregivers were also not correlated with cognitive score.

Regarding the factors related to the total scores of PSI (table 3), caregivers of patients wth $\mathrm{KD}$ who had CAL suffered from greater parenting stress than the caregivers of patients without CAL $(\mathrm{p}=0.019)$. Furthermore, the caregivers who had education levels of a master's degree or above showed less parenting stress than those who had an education level of college $(\mathrm{p}=0.010)$ or lower $(\mathrm{p}=0.021)$. 
Table 1 Characteristics of children with KD and healthy controls

\begin{tabular}{|c|c|c|c|c|}
\hline & $K D(n=176)$ & Controls ( $n=85$ ) & Statistic† & $P$ value \\
\hline \multicolumn{5}{|l|}{ Children's characteristics } \\
\hline Age (months) & $66.5 \pm 39.0$ & $77.3 \pm 38.0$ & -2.114 & $0.035^{\star}$ \\
\hline Age of KD onset (months) & $21.6 \pm 17.7$ & - & N/A & N/A \\
\hline Sex & & & 1.054 & 0.305 \\
\hline Male & $107(60.8)$ & $46(54.1)$ & & \\
\hline Female & $69(39.2)$ & $39(45.9)$ & & \\
\hline Intravenous immunoglobulin & & & N/A & N/A \\
\hline None & $7(4.0)$ & - & & \\
\hline Once & $156(88.6)$ & - & & \\
\hline Twice & $13(7.4)$ & - & & \\
\hline Coronary artery aneurysms & & & N/A & N/A \\
\hline With & $74(42.0)$ & - & & \\
\hline Without & $102(58.0)$ & - & & \\
\hline \multicolumn{5}{|l|}{ Mullen Scales of Early Learning } \\
\hline Gross Motor $\ddagger$ & $52.0 \pm 13.1$ & $52.7 \pm 12.0$ & 0.091 & 0.765 \\
\hline Visual Reception & $54.0 \pm 13.8$ & $53.1 \pm 17.2$ & 0.062 & 0.804 \\
\hline Fine Motor & $50.2 \pm 13.4$ & $50.1 \pm 11.6$ & 0.037 & 0.847 \\
\hline Receptive Language & $57.0 \pm 11.5$ & $51.2 \pm 10.7$ & 3.838 & 0.054 \\
\hline Expressive Language & $51.7 \pm 13.2$ & $50.5 \pm 11.2$ & 0.229 & 0.634 \\
\hline Composite scores & $106.2 \pm 19.4$ & $105.0 \pm 19.2$ & 0.087 & 0.768 \\
\hline \multicolumn{5}{|l|}{ WPPSI } \\
\hline Full Scale IQ & $103.7 \pm 10.4$ & $107.6 \pm 11.7$ & 1.380 & 0.243 \\
\hline Verbal Comprehension Index & $105.2 \pm 10.7$ & $107.1 \pm 14.3$ & 1.132 & 0.290 \\
\hline Visual Spatial Index & $98.8 \pm 14.9$ & $101.5 \pm 10.9$ & 0.262 & 0.610 \\
\hline Fluid Reasoning Index & $107.0 \pm 12.0$ & $107.0 \pm 13.9$ & 0.003 & 0.960 \\
\hline Working Memory Index & $99.0 \pm 12.4$ & $100.3 \pm 15.3$ & 0.150 & 0.700 \\
\hline Processing Speed Index & $103.3 \pm 12.5$ & $106.9 \pm 12.7$ & 0.683 & 0.411 \\
\hline \multicolumn{5}{|l|}{ WISC-IV } \\
\hline Full Scale IQ & $109.1 \pm 11.1$ & $109.7 \pm 17.4$ & 1.039 & 0.311 \\
\hline Verbal Comprehension Index & $108.2 \pm 13.4$ & $111.3 \pm 16.3$ & 0.022 & 0.882 \\
\hline Perceptual Reasoning Index & $106.1 \pm 14.8$ & $106.4 \pm 17.2$ & 0.576 & 0.450 \\
\hline Working Memory Index & $110.3 \pm 13.1$ & $111.4 \pm 15.3$ & 0.331 & 0.567 \\
\hline Processing Speed Index & $103.0 \pm 14.3$ & $98.4 \pm 15.1$ & 3.928 & 0.051 \\
\hline \multicolumn{5}{|l|}{ Caregivers' characteristics } \\
\hline Age (years) & $37.6 \pm 4.8$ & $38.2 \pm 5.0$ & -0.889 & 0.375 \\
\hline Sex & & & 1.096 & 0.295 \\
\hline Male & $26(14.9)$ & $17(20.0)$ & & \\
\hline Female & $149(85.1)$ & $68(80.0)$ & & \\
\hline Education levels & & & 8.080 & $0.018^{\star}$ \\
\hline High school or lower & $81(46.8)$ & $29(34.1)$ & & \\
\hline College & $77(44.5)$ & $39(45.9)$ & & \\
\hline Master or above & $15(8.7)$ & $17(20.0)$ & & \\
\hline Family expenditure (per month)§ & & & 0.515 & 0.773 \\
\hline$<50000$ NT\$ & $94(59.9)$ & $42(55.3)$ & & \\
\hline 50000-100000 NT\$ & $46(29.3)$ & $24(31.6)$ & & \\
\hline
\end{tabular}


Table 1 Continued

\begin{tabular}{|c|c|c|c|c|}
\hline & KD (n=176) & Controls $(\mathrm{n}=85)$ & Statistic† & $P$ value \\
\hline \multicolumn{5}{|l|}{ PSI-SF } \\
\hline Parental Distress & $30.2 \pm 8.2$ & $30.0 \pm 9.0$ & 0.003 & 0.958 \\
\hline Parent-Child Dysfunctional Interaction & $23.1 \pm 7.0$ & $24.4 \pm 8.3$ & 2.204 & 0.139 \\
\hline Total score & $80.7 \pm 20.4$ & $83.1 \pm 21.9$ & 1.749 & 0.187 \\
\hline
\end{tabular}

Data are expressed as mean \pm SD or $\mathrm{n}(\%)$.

${ }^{*} \mathrm{p}<0.05$.

†Statistical values are expressed as $t$ value or $\chi^{2}$

$\ddagger$ Gross Motor is only for children aged $<33$ months.

§NT\$ represents new Taiwan dollars (US\$1=31.1 NT\$). There were 28 missing values (19 patients with ADHD and 9 controls).

ADHD, attention deficit hyperactivity disorder; KD, Kawasaki disease; PSI-SF, Parenting Stress Index-Short Form; WISC-IV, Wechsler Intelligence Scale for Children-Fourth Edition; WPPSI, Wechsler Preschool and Primary Scale of Intelligence.

\section{DISCUSSION}

This study demonstrates the potential effect of $\mathrm{KD}$ heterogeneity on cognitive development and parenting stress. Our data revealed that no significant differences in developmental index, cognitive function or parenting stress between patients with KD and controls. Both IVIG

Table 2 Characteristics of children with KD and their caregivers regarding cognition development of children with KD

\begin{tabular}{|c|c|c|}
\hline & B (95\% Cl) & $P$ value \\
\hline Age (months) & $0.07(-0.01$ to 0.15$)$ & 0.067 \\
\hline \multicolumn{3}{|l|}{ Sex } \\
\hline Male & $1.38(-3.43$ to 6.19$)$ & 0.572 \\
\hline \multicolumn{3}{|l|}{ Intravenous immunoglobulin } \\
\hline None & $3.01(-10.86$ to 16.88$)$ & 0.669 \\
\hline Once & $1.43(-7.25$ to 10.11$)$ & 0.746 \\
\hline Twice & 1 & \\
\hline \multicolumn{3}{|l|}{ Caregivers' characteristics } \\
\hline Age (years) & $-0.07(-0.66$ to 0.52$)$ & 0.824 \\
\hline \multicolumn{3}{|l|}{ Sex } \\
\hline Male & $-5.23(-11.97$ to 1.52$)$ & 0.128 \\
\hline Female & 1 & \\
\hline \multicolumn{3}{|l|}{ Education levels } \\
\hline High school or lower & $-3.73(-12.25$ to 4.78$)$ & 0.388 \\
\hline College & $-1.13(-9.60$ to 7.35$)$ & 0.794 \\
\hline Master or above & 1 & \\
\hline
\end{tabular}

The dependent variable in the multiple linear regression model is a cognitive score (Early Learning Composite Score of the MSEL or the FullScale IQ of the WPPSI or WISC-IV). Data are expressed as B value, $95 \% \mathrm{Cl}$ and $p$ value using multiple linear regression model. Adjusted $\mathrm{R}^{2}$ of this regression model $=0.054$.

KD, Kawasaki disease; MSEL, Mullen Scales of Early Learning; WISC-IV, Wechsler Intelligence Scale for Children-Fourth Edition; WPPSI, Wechsler Preschool and Primary Scale of Intelligence. 
Table 3 Characteristics of children with KD and their caregivers regarding parenting stress of the children's caregivers

$$
\text { B }(95 \% \mathrm{Cl}) \quad \text { P value }
$$

\begin{tabular}{|lll}
\hline Children's characteristics & & \\
\hline Age (months) & $0.01(-0.09$ to 0.11$)$ & 0.834 \\
\hline Age of KD onset (months) & $-0.18(-0.37$ to 0.01$)$ & 0.066 \\
\hline Sex & & \\
\hline Male & $0.37(-5.89$ to 6.63$)$ & 0.907 \\
\hline Female & 1 & 0.874 \\
\hline Intravenous immunoglobulin & & 0.303 \\
\hline None & $1.46(-16.60$ to 19.51$)$ & \\
\hline Once & $-5.92(-17.22$ to 5.39$)$ & $0.019^{*}$ \\
\hline Twice & 1 & \\
\hline Coronary artery aneurysms & & 0.784 \\
\hline Without & $-7.41(-13.59$ to 1.23$)$ & 0.898 \\
\hline With & 1 & \\
\hline Caregivers' characteristics & & \\
\hline Age (years) & $-0.11(-0.88$ to 0.66$)$ & $0.021^{*}$ \\
\hline Sex & & $0.010^{*}$ \\
\hline Male & $-0.57(-9.35$ to 8.21$)$ & \\
\hline Female & 1 & \\
\hline Education levels & & \\
\hline High school or lower & $13.11(2.03$ to 24.20$)$ & \\
\hline College & $14.55(3.52$ to 25.58$)$ & \\
\hline Master or above & 1 & \\
\hline
\end{tabular}

The dependent variable in the multiple linear regression model is the total score of the Parenting Stress Index. Data are expressed as B value, $95 \% \mathrm{Cl}$ and $\mathrm{p}$ value using multiple linear regression model.

${ }^{*} p<0.05$. Adjusted $R^{2}$ of this regression model $=0.072$.

$\mathrm{KD}$, Kawasaki disease.

administration and CAL development were not associated with cognitive profiles of children with KD. In addition, the profiles of parenting stress in caregivers of patients with KD were examined in this study. We found that caregivers' education is associated to parenting stress, and the caregivers of patients who had CAL suffered from greater parenting stress than those of patients without CAL.

In our study sample, $4 \%$ never received IVIG, and $88.6 \%$ and $7.4 \%$ received IVIG treatment, once and twice, respectively. Although IVIG has been established as a standard treatment for $\mathrm{KD},{ }^{8} 4 \%$ of patients still never received such intervention and $7.4 \%$ received IVIG treatment twice due to treatment resistance at the first administration. As the study sample included patients referred from local hospitals of remote areas, some of the patients may have missed the opportunity to be correctly diagnosed and receive IVIG at the critical period. Notably, $10 \%-20 \%$ of patients show resistance to IVIG therapy and are at risk for complications. ${ }^{9}$ Our study population with KD consisted of $42 \%$ patients who exhibited CAL, a higher proportion of CAL than has been reported in this literature. ${ }^{10}$ These studies suggest that approximately $20 \%$ of patients with KD suffer from CAL. ${ }^{47}$ This discrepancy may be due to Kaohsiung
Chang Gung Memorial Hospital being the main medical centre in Southern Taiwan and patients recruited for this study possibly having a higher severity or greater comorbidities than those in general hospitals.

The results of this study show that KD is not related to cognitive impairment sequelae, which was generally consistent with the previous literature ${ }^{19-21}$ Because IVIG reduces vasculitis that presumably underlies any cognitive impairment, we assumed that patients with $\mathrm{KD}$ who had a poor response to IVIG or had developed CAL may be related to a higher severity of systemic vasculitis. ${ }^{13} 14$ However, we found that neither IVIG administration nor CAL development was associated with cognitive performance. In our study population, most patients with KD $(96 \%)$ received IVIG treatment. The case numbers of children who did not receive IVIG (only $4 \%$ ) and treatment resistance $(7.4 \%)$ were too small and it is difficult to make a sufficient comparison. Therefore, a future study with larger sample size is required to verify whether IVIG administration is associated with cognitive outcomes or not. Notably, a nationwide survey in Taiwan previously demonstrated that epilepsy and developmental delay were factors associated with cognitive impairments. ${ }^{21}$ Whether 
physical comorbidities other than KD have a greater influence on cognitive function than KD itself or the disease characteristics of KD warrants further research.

We provide more scientific evidence related to parental stress or mental health of caregivers of patients with $\mathrm{KD}$ and keeping in mind that situation implies more health service. It is noteworthy that patients' caregivers were not assessed during patients' acute phase of $\mathrm{KD}$. The clinical meaning of our findings is that parenting stress of caregivers in children with KD during follow-up was comparable those of control children. Nevertheless, our data revealed that caregivers of patients who had CAL suffered from greater parenting stress than the caregivers of patients who did not have CAL. A previous study from Canada revealed a similar finding with our study. The parents of children with coronary artery complications may have suffered from a greater anxiety level. ${ }^{25}$ The psychological distress is associated with family characteristics, such as family income and maternal education. ${ }^{26}$ Children with persistent CAL may develop complications, ${ }^{11}$ so caregivers may worry, feel stressed and experience helplessness with regard to facing the uncertainty of their children's risk of myocardial infarction and the possibility of sudden death. This finding suggests that the parental stress or mental health of caregivers of patients with CAL require particular assistance. Furthermore, caregivers with an education level of a master's degree or above showed lower parenting stress than those who had education levels of college or lower. This finding may imply that caregivers with high education levels had greater internal or external resources to handle the patients' physical illness. ${ }^{26}$ Alternatively, caregivers with lower education levels may require support or help to fulfil their parenting roles.

This study has certain limitations. First, owing to small case numbers of patients with KD without IVIG or treatment resistance, it is difficult to make a strong conclusion about cognitive impairment. Second, this is a casecontrol study, with a mean interval between $\mathrm{KD}$ onset and assessment for cognition and parenting stress of 40.5 months (ranged from 1 to 159 months). Therefore, the measurement for parenting stress was highly dependent on parental recall. The parenting stress reported herein did not necessarily represent the state of patients' caregivers who take care of patients during the acute onset of $\mathrm{KD}$. Third, CAL was only recorded as a categorical variable (with or without), but the influence of CAL severity on cognition or parenting stress was not assessed in this study. Moreover, we did not record physical comorbidities besides KD. Whether other comorbidities (ie, developmental delay or epilepsy) actually influence or moderate children's cognitive development warrants further investigation. Moreover, an increase incidence of $\mathrm{KD}$ has been observed during the SARS-CoV-2 pandemic. ${ }^{48}$ It suggests that SARS-CoV-2 may trigger a severe hyperinflammatory syndrome, such as paediatric inflammatory multisystem syndrome or KD-like symptoms, in childhood. ${ }^{49}$ The influence of SARS-CoV-2 pandemic on the cognitive profiles of patients with $\mathrm{KD}$ and parenting stress of their caregivers warrants further investigation. Fourth, the KD group and control group were not perfectly matched in age and caregivers' characteristics, and those differences may have influenced the results of this study. Finally, all participants were recruited from a single site, whether this finding can be generalised into other patient populations warrants further investigation.

\section{CONCLUSION}

No significant differences in developmental index, cognitive function or parenting stress between patients with KD and controls. In patients with KD, neither IVIG treatment nor CAL was associated with the cognitive profiles of patients with KD. This result is good news for caregivers and patients with $\mathrm{KD}$, reassuring them that their IVIG response or CAL development will have no effect on their development milestones or cognitive function. However, caregivers of patients with $\mathrm{KD}$ who had CAL may feel stress about unpredictable sequela caused by CAL for their children. These caregivers may require support or help to fulfil their parenting roles.

\section{Acknowledgements The authors thank all participants in this study.}

Contributors L-JW and L-SC: conceptualised and designed the study and drafted the initial manuscript. Z-YT: recruited and assessed the patients. H-CK: designed the study, recruited the patients and approved the final manuscript to be submitted.

Funding This study was supported by a grant from Kaohsiung Chang Gung Memorial Hospital, Taiwan (CMRPG8C1082, CMRPG8E1613, CORPG8F0013, CMRPG8J0611 and CMRPG8D0521).

Competing interests None declared.

Patient and public involvement Patients and/or the public were not involved in the design, or conduct, or reporting, or dissemination plans of this research.

Patient consent for publication Not required.

Ethics approval Chang Gung Memorial Hospital's Internal Review Board approved this study (IRB No. 104-8261C), and we obtained the written informed consent from the parents or guardians of all participating children.

Provenance and peer review Not commissioned; externally peer reviewed.

Data availability statement Data are available upon reasonable request.

Open access This is an open access article distributed in accordance with the Creative Commons Attribution Non Commercial (CC BY-NC 4.0) license, which permits others to distribute, remix, adapt, build upon this work non-commercially, and license their derivative works on different terms, provided the original work is properly cited, appropriate credit is given, any changes made indicated, and the use is non-commercial. See: http://creativecommons.org/licenses/by-nc/4.0/.

ORCID iD

Liang-Jen Wang http://orcid.org/0000-0002-5320-1151

\section{REFERENCES}

1 Newburger JW, Takahashi M, Burns JC. Kawasaki disease. J Am Coll Cardiol 2016;67:1738-49.

2 Hara T, Nakashima Y, Sakai Y, et al. Kawasaki disease: a matter of innate immunity. Clin Exp Immunol 2016;186:134-43.

3 Singh S, Vignesh P, Burgner D. The epidemiology of Kawasaki disease: a global update. Arch Dis Child 2015;100:1084-8.

4 Uehara R, Belay ED. Epidemiology of Kawasaki disease in Asia, Europe, and the United States. J Epidemiol 2012;22:79-85.

5 Zhu FH, Ang JY. The clinical diagnosis and management of Kawasaki disease: a review and update. Curr Infect Dis Rep 2016;18:32. 
6 Rowley $\mathrm{AH}$. The complexities of the diagnosis and management of Kawasaki disease. Infect Dis Clin North Am 2015;29:525-37.

7 Kuo H-C, Yang KD, Chang W-C, et al. Kawasaki disease: an update on diagnosis and treatment. Pediatr Neonatol 2012;53:4-11.

8 Eleftheriou D, Levin M, Shingadia D, et al. Management of Kawasaki disease. Arch Dis Child 2014;99:74-83.

9 Qiu $\mathrm{H}, \mathrm{He} \mathrm{Y}$, Rong X, et al. Delayed intravenous immunoglobulin treatment increased the risk of coronary artery lesions in children with Kawasaki disease at different status. Postgrad Med 2018:130:442-7.

10 Chen KYH, Curtis N, Dahdah N, et al. Kawasaki disease and cardiovascular risk: a comprehensive review of subclinical vascular changes in the longer term. Acta Paediatr 2016;105:752-61.

11 Joshi M, Tulloh R. Kawasaki disease and coronary artery aneurysms: from childhood to adulthood. Future Cardiol 2017;13:491-501.

$12 \mathrm{Kuo} \mathrm{H}-\mathrm{C}$. Preventing coronary artery lesions in Kawasaki disease. Biomed J 2017;40:141-6.

13 Gitiaux C, Kossorotoff M, Bergounioux J, et al. Cerebral vasculitis in severe Kawasaki disease: early detection by magnetic resonance imaging and good outcome after intensive treatment. Dev Med Child Neurol 2012;54:1160-3.

14 Korematsu S, Uchiyama S-ichi, Miyahara H, et al. The characterization of cerebrospinal fluid and serum cytokines in patients with Kawasaki disease. Pediatr Infect Dis J 2007;26:750-3.

15 Hikita T, Kaminaga T, Wakita S, et al. Regional cerebral blood flow abnormalities in patients with Kawasaki disease. Clin Nucl Med 2011;36:643-9

16 Emiroglu M, Alkan G, Kartal A, et al. Abducens nerve palsy in a girl with incomplete Kawasaki disease. Rheumatol Int 2016;36:1181-3.

17 Bailie NM, Hensey OJ, Ryan S, et al. Bilateral subdural collections-an unusual feature of possible Kawasaki disease. Eur J Paediatr Neurol 2001;5:79-81.

18 Constantinescu CS, Migraine CCS. Migraine and Raynaud phenomenon: possible late complications of Kawasaki disease. Headache 2002;42:227-9.

19 King WJ, Schlieper A, Birdi N, et al. The effect of Kawasaki disease on cognition and behavior. Arch Pediatr Adolesc Med 2000;154:463-8.

20 Nishad P, Singh S, Sidhu M, et al. Cognitive and behaviour assessment following Kawasaki disease--a study from North India. Rheumatol Int 2010;30:851-4.

21 Wang L-J, Kuo H-C. Cognitive development after Kawasak disease - clinical study and validation using a nationwide population-based cohort. Circ J 2018;82:517-23.

22 Dietz SM, van Stijn D, Burgner D, et al. Dissecting Kawasaki disease: a state-of-the-art review. Eur J Pediatr 2017;176:995-1009.

23 Kourtidou S, Slee AE, Bruce ME, et al. Kawasaki disease substantially impacts health-related quality of life. $J$ Pediatr 2018;193:155-63.

24 Miura M, Kobayashi T, Kaneko T, et al. Association of severity of coronary artery aneurysms in patients with Kawasaki disease and risk of later coronary events. JAMA Pediatr 2018;172:e180030.

25 Chahal N, Clarizia NA, McCrindle BW, et al. Parental anxiety associated with Kawasaki disease in previously healthy children. $J$ Pediatr Health Care 2010;24:250-7.

26 Chahal N, Jelen A, Rush J, et al. Kawasaki disease with coronary artery aneurysms: psychosocial impact on parents and children. $J$ Pediatr Health Care 2017;31:459-69.

27 Jewell NP. Statistics for epidemiology. Boca Raton: CRC Press, 2003.

28 Newburger JW, Takahashi M, Gerber MA, et al. Diagnosis, treatment, and long-term management of Kawasaki disease: a statement for health professionals from the Committee on rheumatic fever, endocarditis, and Kawasaki disease, Council on cardiovascular disease in the young, American heart association. Pediatrics 2004:114:1708-33.
29 Kuo H-C, Hsieh K-S, Ming-Huey Guo M, et al. Next-Generation sequencing identifies micro-RNA-based biomarker panel for Kawasaki disease. J Allergy Clin Immunol 2016;138:1227-30.

30 Kuo H-C, Wang C-L, Liang C-D, et al. Association of lower eosinophil-related T helper 2 (Th2) cytokines with coronary artery lesions in Kawasaki disease. Pediatr Allergy Immunol 2009;20:266-72.

31 Kuo H-C, Yang KD, Liang C-D, et al. The relationship of eosinophilia to intravenous immunoglobulin treatment failure in Kawasaki disease. Pediatr Allergy Immunol 2007;18:354-9.

$32 \mathrm{Kuo} \mathrm{H}-\mathrm{C}$, Chang J-C, Kuo H-C, et al. Identification of an association between genomic hypomethylation of FCGR2A and susceptibility to Kawasaki disease and intravenous immunoglobulin resistance by DNA methylation array. Arthritis Rheumatol 2015;67:828-36.

33 Mullen EM. Mullen scales of early learning item administration book. Circle Pines, MN: American Guidance Service, 1995.

34 Tsai J-M, Lu L, Jeng S-F, et al. Validation of the modified checklist for autism in toddlers, revised with follow-up in Taiwanese toddlers. Res Dev Disabil 2019;85:205-16.

35 Wechsler D. Wechsler preschool and primary scales of intelligence (4th ed) (WPPSI-IV). San Antonio, TX: Psychological Corporation, 2012.

36 Watkins MW, Beaujean AA. Bifactor structure of the Wechsler Preschool and Primary Scale of Intelligence--Fourth Edition. Sch Psychol Q 2014;29:52-63.

37 Lee Y-C, Lin C-H, Tsai C-H, et al. Association between executing theory of mind in a limited experimental context and executing it in daily contexts in children with autism spectrum disorder: a crosssectional study. Am J Occup Ther 2019;73:7303205150p1-11.

38 Baron IS. Test review: Wechsler intelligence scale for Children-Fourth edition (WISC-IV). Child Neuropsychol 2005;11:471-5.

39 Yang P, Cheng C-P, Chang C-L, et al. Wechsler intelligence scale for children 4th edition-Chinese version index scores in Taiwanese children with attention-deficit/hyperactivity disorder. Psychiatry Clin Neurosci 2013;67:83-91.

40 Wang L-J, Chan W-C, Chou M-C, et al. Polymorphisms of STS gene and SULT2A1 gene and neurosteroid levels in Han Chinese boys with attention-deficit/hyperactivity disorder: an exploratory investigation. Sci Rep 2017:7:45595.

41 Loyd BH, Abidin RR. Revision of the parenting stress index. J Pediatr Psychol 1985:10:169-77.

42 Haskett ME, Ahern LS, Ward CS, et al. Factor structure and validity of the parenting stress index-short form. $J$ Clin Child Adolesc Psychol 2006;35:302-12.

43 Yeh $\mathrm{CH}$, Chen ML, Li W, et al. The Chinese version of the parenting stress index: a psychometric study. Acta Paediatr 2001;90:1470-7.

44 Chen Y-C, Hwang-Gu S-L, Ni H-C, et al. Relationship between parenting stress and informant discrepancies on symptoms of $\mathrm{ADHD} / \mathrm{ODD}$ and internalizing behaviors in preschool children. PLOS One 2017;12:e0183467.

45 Huang $\mathrm{C}-\mathrm{Y}$, Yen $\mathrm{H}-\mathrm{C}$, Tseng $\mathrm{M}-\mathrm{H}$, et al. Impacts of autistic behaviors, emotional and behavioral problems on parenting stress in caregivers of children with autism. J Autism Dev Disord 2014;44:1383-90.

46 Garson G. Testing statistical assumptions. USA: Statistical Associates Publishing, 2012.

47 McCrindle BW, Rowley AH, Newburger JW, et al. Diagnosis, treatment, and long-term management of Kawasaki disease: a scientific statement for health professionals from the American heart association. Circulation 2017;135:e927-99.

48 Cavallo F, Chiarelli F. An outbreak of Kawasaki-like disease in children during SARS-CoV- 2 epidemic: no surprise? Acta Biomed 2020;91:e2020015.

49 Berardicurti O, Conforti A, Ruscitti P, et al. The wide spectrum of Kawasaki-like disease associated with SARS-CoV-2 infection. Expert Rev Clin Immunol 2020;16:1205-15. 